\title{
Erratum to: A hypofunctional PAX1 mutation causes autosomal recessively inherited otofaciocervical syndrome
}

\author{
Esther Pohl • Ayca Aykut · Filippo Beleggia $\cdot$ Emin Karaca $\cdot$ Burak Durmaz $\cdot$ Katharina Keupp • \\ Esra Arslan • Melis Palamar · Gökhan Yigit · Ferda Özkinay • Bernd Wollnik
}

Published online: 25 July 2013

(c) Springer-Verlag Berlin Heidelberg 2013

\section{Erratum to: Hum Genet}

\section{DOI 10.1007/s00439-013-1337-9}

The name of author Melis Palamar Onay was published incorrectly. The correct name should read as Melis Palamar.

The online version of the original article can be found under doi:10.1007/s00439-013-1337-9.

E. Pohl · A. Aykut · F. Beleggia · K. Keupp · G. Yigit · B. Wollnik $(\bowtie)$

Institute of Human Genetics, University Medical Faculty, University of Cologne, Kerpener Str. 34,

50931 Cologne, Germany

e-mail: bwollnik@uni-koeln.de

E. Pohl · F. Beleggia - K. Keupp · G. Yigit - B. Wollnik Center for Molecular Medicine Cologne (CMMC),

University of Cologne, Cologne, Germany

E. Pohl · F. Beleggia - K. Keupp - G. Yigit - B. Wollnik Cologne Excellence Cluster on Cellular Stress Responses in Aging-Associated Diseases (CECAD), University of Cologne, Cologne, Germany

\footnotetext{
A. Aykut · E. Karaca · B. Durmaz · E. Arslan · F. Özkinay Department of Medical Genetics, Faculty of Medicine, Ege University, Izmir, Turkey

M. Palamar

Department of Ophthalmology, Faculty of Medicine,

Ege University, Izmir, Turkey
} 